TIJDSCHRIFT VOOR GENDERSTUDIES

www.tijdschriftvoorgenderstudies.nl

Uitgave: Amsterdam University Press

\title{
In Lak' ech: you are my other me
}

Re-imagining interdisciplinarity as a trans-disciplinary becoming

Aurora Perego and Christine Quinan

TVGN 20 (4): 341-358

DOI: 10.5117/TVGN2017.4.PERE

\begin{abstract}
This article aims to explore the potential of transgender studies to offer new trans* and interdisciplinary perspectives that simultaneously question dominant power structures and engage with multiple and unexpected becomings. We believe that the disruptive force of trans-disciplinarity lies in its capacity to open up space for marginalised populations and knowledges by creating a co-emergence of theories and methodologies that, rather than gathering different disciplines around the same topic, becomes, in Roland Barthes's words, 'a new object that belongs to no one'. The article attempts to reimagine interdisciplinarity as a decolonial trans- practice that questions broader processes of exclusion occurring in academia. Such envisioning will unfold around the concept of intersectionality, which we consider necessary to challenge and transform the exclusions reproduced through disciplinary knowledge production. In this respect, we maintain that interdisciplinarity must be constituted so as to trans-cend and queer not only disciplinary boundaries, but also the processes of normalisation that create them. We combine this theorisation with the Mayan principle of In Lak' ech, which unveils the interdependence of animate and inanimate beings on Earth and thereby has the potential to disrupt not only the notion of 'proper object' that belongs to specific disciplines but also the 'proper subject', namely disciplinary hierarchies per se. The principle of In Lak' Ech allows us to envision transdisciplinary becoming as a practice of intersectional resistance that opens space for radical, trans-, queer, and decolonial social critiques.
\end{abstract}

Keywords: trans*, gender, interdisciplinarity, becoming, decolonial 


\section{Introduction}

In Lak'ech

Tú eres mi otro yo.

You are my other me.

Si te hago daño a ti,

If I do harm to you,

Me hago daño a mi mismo.

I do harm to myself.

Si te amo y respeto,

If I love and respect you,

Me amo y respeto yo.

I love and respect myself.

- Luís Valdez, 'Pensiamiento Serpentino', $1973^{1}$

In October 2016, a number of researchers embedded in various disciplinary areas gathered for an expert meeting under the general heading of the GIRARE (Gender Identity Registration and Human Rights Effects) Project, a collaborative endeavour of Gender Studies and Legal Studies scholars from Utrecht University. Building on theoretical critiques of 'sex' as a constructed category, the project explores the impacts that practices of gender registration play in different sociocultural contexts. One aim of the project is to problematise intersections between dominant notions of 'citizenship' and normative 'sex' or, stated differently, to examine how citizenship and gender 'norms' interact and complicate one other. The project involves empirical and theoretical components that are greatly informed by feminist, queer, trans*, decolonial, and postcolonial perspectives. ${ }^{2}$

Within this framework, the expert meeting was meant to bring together the expertise of several international scholars in order to create an interdisciplinary environment that would contribute to outlining future steps for the project. On that occasion, we were nonetheless reminded of the challenges of interdisciplinary research, which range from sharing terminologies and time (of which there seems to never be enough) and to being accountable and open towards one another's methodological practices and ontological premises. Understandings of (how to trigger and achieve) social change seemed to vary from discipline to discipline more than what we might have, perhaps naively, expected. When the discussion deepened, one participant directly asked if the project's ultimate goal was to 'undo the system'. Assuming that 'the system' could stand for 'imperialist white supremacist capitalist patriarchy' (hooks, 2013), we responded 
with a positioned and affirmative response, to which the participant reacted: 'We cannot aim at changing something. We are researchers, and research takes time. One cannot be a researcher and an activist. One is either a researcher or an activist'. ${ }^{3}$

Such assumptions are nonetheless challenged by the perspectives articulated within transgender studies, which was established in the early 1990 s as 'an activist process as well as an explorative process' (Stryker \& Whittle, 2006, p. xv). Susan Stryker and Paisley Currah summarise the broader aims in the following terms: 'transgender does not simply critique present configurations of power/knowledge; it is engaged with all manner of unexpected becomings, oriented toward a future that, by definition, we can anticipate only imperfectly and never fully grasp' (2014a, p. 9). To achieve such goals, this scholarship has engaged with interdisciplinary bodies of knowledges, hence configuring innovative epistemological perspectives and methodological practices. Against this backdrop, this article intends to reflect on the possibilities and limitations posed by the concept of interdisciplinarity, first in relation to the GIRARE Project, and then in the context of transgender studies. We chose to begin from the brief example of the expert meeting to locate ourselves and our work in relation to the topics addressed throughout the article. While our backgrounds are geographically, academically, and professionally different, the varying intersections of marginalisation we experience are counterbalanced by our white privilege, citizenship status, and positions held in academia. In reflecting on the difficulties and challenges we encounter in our daily work within the GIRARE Project, we are able to explore the potential of transgender studies to offer new trans* and interdisciplinary perspectives able to simultaneously question dominant power structures and engage with 'unexpected becomings'. With regard to the twofold goals pursued by transgender studies, we ask: how could interdisciplinarity be envisioned in order to both question hegemonic economies of power and trigger alternative ways to generate knowledge? Might transgender studies scholars address interdisciplinarity not simply as a methodological tool, but also as a theoretical space with the potential to transform exclusionary boundaries functioning outside and inside academia? The words of French philosopher Roland Barthes on interdisciplinarity seem particularly apt here:

Interdisciplinary work, so much discussed these days, is not about confronting already constituted disciplines (none of which, in fact, is willing to let itself go). To do something interdisciplinary it's not enough to choose a 'subject' (a 
theme) and gather around it two or three sciences. Interdisciplinarity consists in creating a new object that belongs to no one. (1972, p. 3)

Barthes argues that interdisciplinary research does not aim to combine different approaches, but rather to disrupt the mechanisms through which academic differences are inscribed within hierarchies, including disciplinary boundaries. Barthes's insights combined with trans and decolonial studies that work to disrupt hegemonic power dynamics that exclude subjugated knowledges and marginalise communities trigger us to configure strategies that might undo disciplines and re-articulate interdisciplinarity towards non-normative imaginaries.

Walter Mignolo has emphasised (2002; 2009) that only through decolonial perspectives is it possible to disarticulate the Western 'scientific' apparatus that was historically built on white supremacy and systematic debasement of non-Western knowledges and populations. However, as Stryker and Currah (2014b) point out in the introduction to a special issue of Transgender Studies Quarterly entitled 'Decolonizing the Transgender Imaginaries', discussions on colonialism and coloniality have been lacking within transgender studies:

How can engaged scholarship combine with inspirational pedagogies to inculcate decolonial perspectives or political activism among students doing transgender studies coursework, with consequences that extend well outside the classroom? How might decolonial strategies emanating from many sites of resistance and struggle throughout the world disseminate themselves through formal as well as informal education, academic as well as community-based research, and scholarship that draws on legitimated knowledges as well as subjugated ones? How could attention to decolonization in this moment of rapid institutionalization for transgender studies as an academic field leave an imprint that shapes institutional culture for a long time to come, or contribute to the redirection of institutional resources toward goals or groups that historically have been excluded from the university? (2014b, p. 306)

We quote this passage at length because it is in this respect that this article proposes an attempt to reimagine interdisciplinarity as a decolonial transpractice that questions processes of (disciplinary) exclusion and creates space for differently marginalised populations and knowledges. Inspired by Stryker's trans-formative use of the Deleuzian concept of 'becoming', we are interested in articulating the concept of 'trans-disciplinary becoming' as 'an improvisational, creative, and essentially poetic practice through 
which radically new possibilities for being in the world can start to emerge' (Stryker, Currah, \& Moore, 2008, p. 14). To achieve this aim, we begin by interrogating interdisciplinary research from a Foucauldian understanding of disciplines as hierarchical fields of power that are entangled in intersectional systems of oppression. By looking at interdisciplinarity through the concept of intersectionality (Crenshaw, 1989), we aim to explore how constructed narratives of 'scientific value' are inherently intertwined with asymmetries of race, gender, and sexuality that exclude or marginalise certain knowledges and populations from the academic sphere. After problematising the exclusionary power of disciplines, we argue for the necessity to articulate interdisciplinarity as 'intersectional resistance' (Spade, 2013).

By combining insights from Stryker's understanding of 'trans-' as a nonhierarchical movement (Stryker, Currah, \& Moore, 2008) with Pryse's claim for a 'transversal feminist methodology' (2000), the second section will then scrutinise how interdisciplinarity may be transformed as simultaneously rooted and rootless practices of becoming. We will then conclude by envisioning interdisciplinarity as 'trans-disciplinary becoming' through the Mayan principle of In Lak' ech, an ancient precept translated as 'You are my other me' (Tu eres mi otro yo). Aware that indigenous knowledges have been alternatively critiqued and romanticised, our approach towards In Lak' ech resists appropriation. In other words, our aim is not to 'accommodate' Mayan knowledge within the Western-centric scholarship in which our research is inscribed. On the contrary, In Lak' ech points at the fallacy of the disciplinary boundaries on which such scholarship is built and (re)produced as an exclusionary apparatus. By unveiling the interdependence of animate and inanimate beings on Earth, In Lak' ech has the potential to disrupt not only the notion of a 'proper object' that belongs to specific disciplines, but also that of the 'proper subject' (i.e. disciplinary hierarchies per se). In this respect, it emerges as a desubjugated knowledge (Stryker \& Whittle, 2006) that articulates a decolonial disruption of Western academic models based on disciplines that transgender studies likewise aims to trespass and subvert. Therefore, In Lak' ech provides us with the theoretical strength to imagine trans-disciplinary becoming as a conceptual dimension through which transgender studies can question and transform academic exclusions. 


\section{Interdisciplinarity: Between academic disciplining and intersectional resistance}

In the last decades, the concept and practice of interdisciplinarity has increasingly gained academic attention for being 'both an embattled site of controversy and a new battle cry' (Hutcheon, 1997, p. 19). Debates have concerned not only the methodological prospects and pitfalls of interdisciplinary research, but have also arisen due to different understandings of its ontological and epistemological dimensions: namely, what interdisciplinarity is and what it does. Despite an initial rather uncritical approach to interdisciplinary practices within feminist scholarship (Pryse, 2000), several scholars ${ }^{4}$ have recently questioned Women's Studies, Gender Studies, and even Queer Studies for re-establishing (disciplinary) boundaries rather than articulating strategies to cross or blur them. The main points that have been raised reference how established disciplinary areas - regardless of their claims to be inclusionary or radical - implicitly rely on hierarchical notions of 'proper object' and 'proper subject' to gain academic recognition and legitimacy. In this respect, 'proper' objects and subjects are conceptualised as mutually exclusive categories constituted through hierarchical relationships between the research topic, the researcher(s), and the field of research, rather than as interdependent and equally important components of knowledge production. Within this framework, we cannot assume that, through the mere combination of diverging theoretical approaches and methodological practices, interdisciplinarity necessarily defies the vertical foundations of disciplines.

Following on Foucault, 'disciplines characterize, classify, specialize; they distribute along a scale, around a norm, hierarchize individuals in relation to one another and, if necessary, disqualify and invalidate' (1975, p. 223). In other words, established disciplines are both the result and vehicle of 'disciplining', a process that functions as an exclusionary field of power. By circumscribing and establishing borders according to constructed narratives of 'scientific value', disciplinary boundaries mark who and what 'counts', both as 'subject' and as 'object'. They concomitantly (re) produce certain topics and categories as 'deserving', making them 'properties' of specific academic areas, while excluding other knowledges and populations from both the domain of who can think and represent (i.e. 'proper subjects') and what is thinkable and representable (i.e. 'proper objects'). According to Foucault, knowledges that have been disqualified as not matching established standards of erudition are 'subjugated' by the very processes that determine what 'scientificity' actually is (1980, p. 82). 
Conforming to this understanding, 'subjugated knowledges' refer to 'historical contents that have been masked or buried in functional coherences or formal systematizations' (cited in Stryker \& Whittle, 2006, p. 12). They also, however, encompass all sorts of 'traditional' and 'popular' beliefs that cannot be 'objectively' proven and are, hence, constructed as 'inferior'.

What knowledges are, hence, (not) reproduced as 'deserving' and 'scientific'? What subjectivities are materialised as 'knowers' and what as 'known'? First theorised by Kimberlé Crenshaw in 'Demarginalizing the Intersection of Race and Sex: A Black Feminist Critique of Antidiscrimination Doctrine, Feminist Theory and Antiracist Politics' (1989), the concept of intersectionality offers a powerful analytical frame to scrutinise how asymmetries of gender, race, class, sexuality, dis/abilities, age ${ }^{5}$ interact to privilege certain subjects while marginalising others. Stated otherwise, intersectionality emphasises how differential axes of privilege and marginalisation co-articulate each other in the reiteration of societal 'norms'. Furthermore, as Crenshaw insightfully asserts, intersectionality challenges so-called 'single-axis' approaches, which fail to address the hegemonic entanglements through which subjectivities are materialised as always already 'others'. This point is further articulated by Spade (2013), who argues that invocations of human rights cannot protect discriminated populations if advocates fail to recognise that different forms of violence and subjection are intersectionally connected. While framing single-axis 'equality agendas', they not only depoliticise political struggles, but participate in the logics of intersectional violence by 'dividing constituencies', i.e. by inscribing populations into static disciplinary categories opposed to one other. Such disciplining is (re)produced through implicit hierarchical notions of normative 'deservingness' that 'sort populations into those whose life must be cultivated and protected and those cast as threats and drains' (Spade, 2013, p. 1050). The process that Spade metaphorically describes as a 'distribution of life chances' sets the boundaries between 'worthy' and 'unworthy' lives. On the one hand, it controls access to material goods and resources, while, on the other, it marks out 'those who do not count' from the possibility to be seen and heard.

As Cho, Crenshaw, and McCall (2013) maintain, intersectionality has travelled and transformed into a conceptual tool to analyse the complexity of subject formation, identity politics, and knowledge production. Aware that intersectional debates are themselves entangled in power structures (academic or otherwise), we argue that looking at Foucauldian disciplining through an intersectional lens has the potential to unveil that the latter reinscribes the creation of knowledge into dominant (intersecting) dis- 
courses of normativity. Knowledge production, knowing, and disciplines are deeply intertwined in societal modes of governance that privilege 'normative' - white, Western, cisgender, male, abled, propertied - subjectivities as the 'knowers', i.e. the only ones able to create 'scientific episteme'. 'Non-normative' populations are, on the contrary, reduced to the position of 'objects' whose knowledge is systematically devaluated. Disciplinary processes can thus be seen as intersectional fields of power that function along broader structures of subjectivation. In this respect, as Eng, Halberstam, and Muñoz (2005) maintain, if interdisciplinarity is limited to gathering different epistemological and methodological perspectives around the same topic without contesting their boundaries, it may not be able to defy notions of academic hierarchies that stem from intersectional power structures and that are reinforced through disciplining. Paraphrasing Roderick Ferguson's commentary on the study of 'sex' and 'gender' within the field of queer studies, they assert: 'As interdisciplinary sites such as queer studies isolate sexuality within one epistemic terrain [...] or attempt to arrogate sexuality to themselves alone, these sites proved interdisciplinarity's complicity with disciplinarity rather than interdisciplinarity's rebellion against the disciplines' (Eng, Halberstam, \& Muñoz, 2005, p. 88).

However, interdisciplinarity might nonetheless be a powerful tool to disrupt disciplining as an exclusionary field of power. In this regard, rather than building on an understanding of interdisciplinary research as either 'normative' or 'subversive', we argue that it is through an awareness of its twofold, perhaps contradictory, significance that interdisciplinarity can be re-envisioned and re-imagined not merely as method, but as a conceptual space that articulates alternatives to academic 'discourses of deservingness' (Spade, 2013, p. 1037). By merging the concepts of intersectionality and interdisciplinarity, namely as interdisciplinary-intersectional resistance, we might thus be able to situate interdisciplinarity within the matrix of power that creates 'subjugated knowledges'. In her seminal text '(De)Subjugated Knowledges', Susan Stryker (Stryker \& Whittle, 2006) applies Foucault's conceptualisation to transgender studies, arguing that:

Both erudite scholarship and delegitimated 'knowing' recapture, for use in the present, a historical knowledge of particular structurations of power. One offers a 'meticulous rediscovery of struggles,' while the other preserves 'the raw memory of fights.' Transgender studies, through desubjugating previously marginalized forms of knowledge about gendered subjectivity and sexed embodiment, promises such a radical intervention. (p. 13) 
Such a disruptive process of desubjugation might nonetheless be supported by interdisciplinary research. In this regard, as we will further explain and maintain in the next section, intersectionality also offers a peculiar angle to envision interdisciplinarity as a movement that is simultaneously 'rooted' in accountability but is 'rootless' in that it is able to blur disciplinary divisions by trans-cending academic narratives of deservingness that build hierarchies within 'subjects', 'objects', and 'methods'. Ultimately, we maintain that interdisciplinary-intersectional resistance entails the necessity to re-imagine interdisciplinarity as a conceptual practice that moves beyond 'combining' various theories and methods, so as to blur differences while remaining accountable to the privileges and marginalisations upon which every 'proper' position is constructed. In other words, interdisciplinary intersectional resistance could become a practice of desubjugation.

\section{Trans-forming interdisciplinarity}

In articulating the relationship between interdisciplinarity and the propertisation $^{6}$ of methods and theories by established disciplines, sociologist Marjorie Pryse (2000) interestingly takes as her point of departure the etymology of the prefix 'trans-'. According to its Latin origin, this can be read as both a preposition (meaning 'across, over, beyond, or above') (Pryse, 2000, p. 105) and a verb (signifying the movement of passing through something, or overcoming). By examining interdisciplinarity through a 'trans' lens, Pryse reads 'inter' disciplinarity as itself a site of 'trans', 'a place from which we may embark, a site of trans/port and of trans/formation' (2000, p. 105). In what she defines as a 'journey of critical inquiry' (p. 114), the relevance of the 'trans' dimension 'becomes that of transgression, "trans" as a stepping across limits, as trespass (a crossing over), as transcription (a writing over), as transduction (a leading across), as trans-ference (a shifting or making over)' (2000, p. 114). Drawing from Nira Yuval-Davis's model of cross-cultural dialogue known as 'transversalism', Pryse understands 'trans' as an oscillation between the 'rooting' and the 'shifting'; originating from an accountable analysis of the power of disciplining, it is a process that moves not only across, but more importantly beyond the narratives of deservingness or legitimacy associated with established disciplines. Within this framework, 'trans' becomes a transformative practice that lets interdisciplinary research loose from disciplinary boundaries and re-designs it as a transversal feminist methodology that combines 'rooting' and 'shifting': it is therefore both 'rooted' and 'rootless'. 
Similar insights have been proposed by Stryker, Currah, and Moore, who envision 'trans-' as a 'space of connection and circulation' (2008, p. 14) where the hyphen crucially emphases its relational capacity to trans-gress and trans-form disciplinary frontiers, which may be represented by binary gender norms as well as by any other form of biopower that determines who/what counts (and consequently who/what does not). If, as we have maintained above, academic disciplining can be understood as complicit in multiple aspects of intersectional violence, then it becomes necessary to envision 'trans-' not only as an innovative and inclusionary methodology (as argued by Pryse), but also as a theory of interdisciplinarity that transpasses, trans-gresses, and trans-forms disciplining by reading it in light of broader processes of in/exclusions occurring inside and outside universities. Further reflection on these questions emerges from a roundtable dialogue on 'transpedagogies' that was organised and moderated by Vic Muñoz and Ednie Kaeh Garrison (2008). Here, they enquire into the possibilities of envisioning transdisciplinary knowledges through a trans-cending and trans-forming of disciplines with explicit connection to transgender studies. In their terms, they wonder:

Can we analogize transdisciplinarity and transgendering? Disciplinary regimes seek to regulate bodies, minds, practices. Substituting 'transgender practice' for 'transdisciplinary scholarship': in what ways might transgendering require 'learning other languages, traditions, or practices, with the hope that these experiences can integrate with and transform conventional ways of knowing and doing'? Can transgendering subjects 'explode the arbitrary categorical restraints' of discipline/gender? [...] What kinds of legibility and legitimacy do we need in order to collaborate within and across disciplinary regimes and to experience our trans-ness as opportunity, freedom, and creativity? (Muñoz \& Garrison, 2008, p. 298)

In other words, what these scholars interrogate is the possibility of creating trans-gressive theories that not only depart from material and conceptual experiences of trans* populations, but also trans-cend and trans-form the narratives of deservingness marked by processes of disciplining. By combining such insights with the transversal methodology of 'rooting' and 'shifting' developed by Pryse, we argue that conceiving interdisciplinarity as transdisciplinarity does not merely articulate methods between (inter) disciplinary fields but also opens up spaces beyond -trans - the 'legitimacy' of established disciplines. In this respect, an accountable trans-passing of disciplines may carry the potential to trans-form the mutually exclusive 
relations between 'proper subjects' and 'propertied objects', as well as 'academia' and 'activism', so as to create knowledges that, paraphrasing Barthes, cannot be owned or appropriated. It is against this theoretical backdrop that Stryker, Currah, and Moore (2008) articulate 'trans-' as a creative and relational movement that emerges from the trans-gression and trans-formation of frontiers created, amongst other exclusionary practices, upon and through hierarchical notions of 'scientific value'.

The questions cited in the above quote, yet left unanswered by the scholars who participated in the roundtable on transpedagogies, strongly resonate with some of the reflections developed under the GIRARE Project with which we began this article. This interdisciplinary project intends to contribute to the creation of an episteme that is at once transformative and subversive of dominant power structures. Importantly and not causally, in addition to representing the acronym that summarises the research focus (Gender Identity Registration and Human Rights Effects), the Italian word girare means both 'to travel' or 'to move around' and 'to turn'. In this regard, girare carries more than a simply lexical dimension, but owes its raison d'être to its twofold reference to the practice of moving and turning on the one hand, and of blurring boundaries and overturning meanings on the other. In the project, 'trans-' is understood not only as a rooted position, but as a rootless positionality that is able to move across and beyond disciplines. Conscious of the power dynamics reinforced through the academic environment in which we work, we nonetheless maintain that the interdisciplinary research conducted through the project aims not only at disrupting cisnormative matrices, but also at unveiling the structures of intersectional violence upon which the traditional notions of 'proper subjects' and 'proper objects' have arbitrarily excluded trans* individuals from the academic domain. Through the challenges posed by practicing, instead of merely applying, interdisciplinarity, so as to move beyond boundaries and create inclusionary knowledge with and on trans* subjectivities, the project itself has required a new envisioning of interdisciplinarity that, rather than a gathering of methods, must become a theoretical space that carries the potential to trans-cend, trans-gress, and trans-form dominant narratives of deservingness. In our account, trans-forming interdisciplinarity means trans-cending the 'disciplinary' confines implicitly contained in the basic idea of merely 'combining' methods and theories. Rooted in practices of accountability meant to question the marginalisations created by academic disciplining, we intend to trans-cend and trans-form the disciplines in which our expertise is embedded in order to create fluid knowledges able to trans-pass frontiers, and make space for the 'invisible', 'un- 
thinkable', and 'illegitimate' that have been erased through practices of (academic) intersectional violence.

\section{In Lak' ech and trans-disciplinary becoming}

The new envisioning of interdisciplinarity we articulate intends to deconstruct the entanglement of the propertisation of specific methods and topics 'owned' by disciplines, and the concomitant exclusions of knowledges that do not conform to narratives of deservingness and 'scientific' value. To do so, we consider it crucial to turn to the work of indigenous studies scholar Michael Doxtater, who focuses on knowledge as a means of (neo-)colonisation by analysing how 'colonial power-knowledge communicates particular cultural presuppositions that elevate Western knowledge as real knowledge while ignoring other knowledge' (2004, p. 619). In the context of our work, we read the concept of colonial power-knowledge alongside what Argentine feminist philosopher María Lugones conceives of as the 'coloniality of gender' (2007), namely the violent introduction of a Western-centric and hierarchical gender system that was deployed during colonial endeavours as a way to both control and dehumanise colonised populations. One of the assumptions on which the coloniality of gender lies is the binary nature of 'sex', understood as a biological and fixed category that disciplines bodies as either 'male' or 'female'. Lugones argues that the colonial gender system has also worked to eradicate ancient indigenous understandings of individuals who did not 'fit' the sex dichotomy violently imposed by the colonisers. In other words, it has functioned as a colonising means of power-knowledge meant to erase the material and conceptual existence of trans* populations, by configuring the notion of a gendered (either 'male' or 'female') personhood. In this respect, Stryker maintains the following:

The mysterious mujerados and morphodites who populate the earliest accounts of European exploitation of the American continents are not simply (or perhaps even actually) vanished or suppressed members of 'third genders' eradicated by genocidal European practices; they are, just as importantly, categories of deviant personhood constructed by a European imaginary and invested with the magical power to condense and contain, and thereby delimit, a more systemic European failure to grasp a radical cultural otherness in its totality. (Stryker \& Whittle, 2006, p. 14) 
Western white 'science' relegated trans* colonised subjectivities to the domain of the 'deviant' and 'non-human'. According to Mignolo (2009), colonial knowledge production was deeply engaged with disciplining lives and bodies as either 'human' or 'non-human'. Consequently, in his opinion, 'the decolonial option place human lives and life in general first rather than making claims for the "transformation of the disciplines" (2009, p. 177). In line with this insight, we understand the necessity to decolonise given notions of 'sex' and (trans*) 'identity' as a way to '(re) name, (dis)articulate, and (re)assemble the constituent elements of contemporary personhood' (Stryker \& Currah, 2014a, p. 9). Combining the work of Stryker, Spade, and Mignolo unveils once more how the notion of contemporary personhood has often been constructed on and through discrete markers of division, rather than fluidity and connection. In other words, what we have referred to as 'disciplining' functions as an ontoepistemological tool to determine what and who the 'norm' is, which is often constructed in opposition to those cosmologies and existences that are excluded. It is along the fixity of dominant narratives of deservingness that Western (neo)colonial knowledges trigger exclusionary understandings of personhood, and it is precisely the static position of academic disciplines, entrenched behind the 'legitimacy' of their 'scientific value', that we intend to deconstruct through an alternative envisioning of interdisciplinarity.

In aligning ourselves with Mignolo's invitation to engage in decolonising knowledge by problematising 'scientific' dehumanisation, we have been particularly inspired by the timeless Mayan precept known as In Lak' ech, and translated as 'Tu eres mi otro yo' (You are my other me). Reproposed by the Chicano writer Luís Valdez after years of oblivion due to the white colonisation of education and curricula, the concept of In Lak' ech inspired the foundation of the Mexican American Studies Program in Tucson, Arizona (U.S.), an academic decolonial endeavour that was dramatically banned by public authorities in 2012. ${ }^{7}$ Together with two other principles (Panche Be - to seek the root of the Truth, and Hunab Ku Grand Architect of the Universe), In Lak' ech forms the ethical core of 'maiz-based knowledge', a 7,000-year-old episteme based on the assumption that all beings on Earth are connected through the cultivation of corn, understood as both a means of survival and the result of the cohabitation of living creatures. The ancient roots of In Lak' ech have been explored by Arnoldo Vento, who interprets the concept as follows: 'In Lak Ech is the principle of love and respect for your fellow human being. It humanizes humankind by eliminating the ego. It unites as opposed to disuniting; it 
humanizes as opposed to dehumanization and fragmentation' (cited in Rodriguez, 2010, p. 7).

Without contending that a 'maiz-based knowledge' can be directly applied to the Western context, the philosophy developed around In Lak' ech emerges as a desubjugated knowledge with the potential to articulate a decolonial trans-formative becoming that permeates dehumanising frontiers and fragmentation. Drawing on the notion of becoming proposed by Gilles Deleuze and Felix Guattari ([1980] 1987), trans studies scholar T. Garner (2014) argues that such a concept unveils the artificial construction of the binary 'sex' system, and therefore challenges the assumption that trans* bodies are per se 'unnatural', i.e. exceeding the domain of 'gendered personhood'. According to Garner, becoming:

$[\mathrm{P}]$ rovides a destabilization of being and the structures of power associated with it. Here, becoming is both an ontological and an ethical position that involves movement from stable, 'molar' entity to indeterminable, 'molecular' nonidentity, extending beyond the limits of dominant corporeal and conceptual logics. (2014, p. 30)

Becoming, thus, supposes a movement from fixity to fluidity whose trajectories and results are essentially unpredictable. However, as Garner argues, engaging with the notion of becoming as an interrogation of power structures and subject formation requires a focus on exclusionary borders established between as well as within bodies, 'because it is these demarcations that shape bodies and their (trans)formations' (2014, p. 31). To express its trans-gressive and trans-formative potential, becoming must be articulated as a movement that is rooted in accountable practices that challenge (one's) privileges and marginalisations; it must also be capable of shifting to creative processes that create space for different positionalities that diverge from the 'norm' (e.g.)। 'deviant personhood' as expressed by Stryker (Stryker \& Whittle, 2006)). In this respect, it is crucial to remember that 'this approach repudiates an individualized conception of the body and the self; there is no "us versus them" [...] to the extent that none of these terms is intelligible without the others' (Garner, 2014, p. 31).

Stemming from this framework, we understand the principle of In Lak' ech as a becoming upon which a new envisioning of interdisciplinarity can unfold within transgender studies. With its concomitantly deconstructive and unitary dimension of the self, which is re-articulated as not solely a 'human' self and which is composed of different elements present on Earth, the Mayan principle offers an alternative view on humankind and 'human- 
ness' that is constituted through mutual relations with the 'other'. The 'other' becomes the 'self', while the 'self becomes the 'other'. Every hierarchy between the two is undone through the crucial awareness of the inescapability that links them: 'If I do harm to you, I do harm to myself. If I love and respect you, I love and respect myself. In accordance with the ancient rooting of In Lak' ech, we see this precept not as a position or a fixed path to follow, but as a cultivation of critical consciousness in constant becoming, realised through a continuous engagement with dominant power structures and alternative cosmologies, beings, identities, and practices. Looking at interdisciplinarity, In Lak' ech leads to its (re)envisioning as 'trans-disciplinary becoming', which we consider as a conceptual space that trans-passes and trans-forms the narratives of deservingness implied and reinforced through the academic disciplining discussed above. By undoing the rigid boundaries that delimit and delineate disciplines, the concept of 'trans-disciplinary becoming' questions the appropriation and propertisation of theories and methods that enact hierarchical notions of 'scientificity'. In so doing, it opens space for previously marginalised subjectivities to 'belong' to the academy, i.e. to undo the constructed notion of 'deviant personhood' so as to account for an inclusively blurred personhood. In other words, we contend that In Lak' ech has the potential to defy the borders that have delimited trans* subjectivities from the domain of 'personhood' by proposing personhood-in-becoming that is neither internally divided nor externally exclusionary. A trans-disciplinary becoming, thus, is a subversive and creative movement that collectively allows for new (im)possible and (un)expected belongings.

\section{Conclusion}

Drawing from our research experiences within the interdisciplinary GIRARE Project, this article has attempted to articulate a located standpoint on the theorisation of interdisciplinarity within transgender studies. Starting with a problematisation of disciplines, our analysis has maintained that interdisciplinarity needs to be re-imagined as a theoretical space able to question the intersections between academic knowledge production and societal asymmetries of race, gender, and sexuality. Our imaginative effort has been profoundly inspired by In Lak' ech, a Mayan concept which formulation disrupts the exclusionary mechanisms on which 'scientific' Western scholarship is based. By merging In Lak' ech with transformative 
understandings of 'becoming' articulated within transgender studies, we have re-envisioned interdisciplinarity as a trans-disciplinary becoming.

By rooting and unrooting our positions through constant reflections on and negotiation of the privileges that we reproduce as researchers, we hope to have developed a theoretical perspective that, while not belonging to us or to any discipline in particular, triggers an interconnected chain that will continuously become with every person, method, and theoretical framework inspired by it. In other words, rephrasing Deleuze and Guattari ([1980] 1987), we intend that it will change, contaminate, and multiply as a rhizome which unpredictable growth leads to unexpected results. On this note, we would like to conclude with a call for further research into exploring the links between the academic 'field' of transgender studies and (subjugated) indigenous knowledges so as to interrogate alternative possibilities to transgress and transform the various notions of modern personhood that intersectionally disavow certain (non-) human beings on Earth.

\section{Notes}

1. Available at: https:/pakalahau.files.wordpress.com/2012/05/pensamiento-serpentino.pdf.

2. For further information on the project, see The GIRARE Project (2017).

3. Except for the last sentence, which reflects the speaker's exact words, the reported conversation paraphrases the main idea expressed.

4. Such criticism has been articulated from various epistemological standpoints. For insights by scholars working within Women's Studies, see Allen and Kitch (1998) and Bird (2001). For perspectives developed within Queer and Transgender Studies, see Butler (1994) and Stryker (2007).

5. Drawing on Cho, Crenshaw, and McCall (2013), this is not meant to be an exhaustive and definite list of the asymmetries that determine marginalisation and privilege. Intersectionality is indeed a concept able to "capture and engage contextual dynamics of power' (p. 788) that include every sort of constructed differences and hierarchies.

6. By using the expression 'propertization', we intend to account for not only the 'mere' privatisation of methods and theories within the established boundaries of certain disciplines, but also to the very process that constructs them as (potential) properties. It is against this backdrop that we aim to re-articulate interdisciplinarity as a space that directly questions the discursive structures (also known as disciplinary boundaries) that create 'propertied' subjects and 'objects'.

7. For more information on the shutdown of the Programme and consequent protests, please refer to Acosta and Mir (2012), Espinoza-Gonzales et al. (2014), Rendón (2009), and Villanueva Toscano (2013). 


\section{Bibliography}

Acosta, C., \& Mir, A. (2012). Empowering young people to be critical thinkers: The Mexican American 15 studies program in Tucson. Voices in Urban Education, 34, 15-26.

Allen, J.A., \& Kitch, S.L. (1998). Disciplined by disciplines? The need for an interdisciplinary research mission in women's studies. Feminist Studies, 24(2), 275-299.

Barthes, R. (1972). Jeunes chercheurs. Communications, 1, 1-5.

Bird, E. (2001). Disciplining the interdisciplinary: Radicalism and the academic curriculum. British Journal of Sociology of Education, 22(4), 463-478.

Butler, J. (1994). Against proper objects. Introduction. Differences. A Journal of Feminist Cultural Studies, 6(3+2), 1-26.

Cho, S., Crenshaw, K.W., \& McCall, L. (2013). Toward a field of intersectionality studies. Theory, applications, and praxis. Signs: Journal of Women in Culture and Society, 38(4), 785-810.

Crenshaw, K. (1989). Demarginalizing the intersection of race and sex: A black feminist critique of antidiscrimination doctrine, feminist theory and antiracist politics. The University of Chicago Legal Forum, 1, 139-167.

Deleuze, G., \& Guattari, F. ([1980] 1987). A thousand plateaus: Capitalism and schizophrenia. Minneapolis: University of Minnesota Press.

Doxtater, M.G. (2004). Indigenous knowledge in the decolonial era. American Indian Quarterly, 28 $(3 / 4), 618-633$.

Espinoza-Gonzalez, D., French, K.B., Gallardo, S., Glemaker, E., Noel, S., Marsura, M., Mehary, E., Saldaña-Spiegle, N., Schimpf, B., \& Thaw, C. (2013). Decolonizing the classroom through critical consciousness. Navigating solidarity en la lucha for Mexican American Studies. The Educational Forum, 78(1), 54-67.

Eng, D.L., Halberstam, J., \& Muñoz, J.E. (Eds.) (2005). What's queer about queer studies now? Durham: Duke University Press.

Foucault, M. (1975). Discipline and punish. The birth of the prison. New York: Vintage Books.

Foucault, M. (1980). Power/knowledge: Selected interviews and other writings 1972-1977. New York: Pantheon Press.

Garner, T. (2014). Becoming. TSQ: Transgender Studies Quarterly, 1(1\&2), 30-32.

hooks, b. (2013). Writing beyond race. New York: Routledge.

Hutcheon, L. (1997). Disciplinary formation, faculty pleasure, and student risks. ADE Bulletin, 117 (Fall), 19-22.

Lugones, M. (2007). Heterosexualism and the colonial / modern gender system. Hypatia, 22(1), 186-208.

Mignolo, W. (2002). Geopolitics of knowledge and the colonial difference. South Atlantic Quarterly, $103(1), 57-96$.

Mignolo, W. (2009). Epistemic disobedience, independent thought and decolonial freedom. Theory, Culture \& Society, 26(7-8), 159-181.

Muñoz, V., Garrison, E.K. (2008). Transpedagogies: A roundtable dialogue. WSQ: Women's Studies Quarterly, 36(3\&4), 288-308.

Pryse, M. (2000). Trans/feminist methodology: Bridges to interdisciplinary thinking. NWSA Journal, 12(2), 105-118.

Rendón, L.I. (2009): Sentipensante (sensingthinking) pedagogy. Educating for wholeness, social justice and liberation. Sterling: Stylus Pub.

Rodriguez, R. (2010). Amoxtli $X$ - The X codex. Austin: Eagle Feather Research Institute.

Spade, D. (2013). Intersectional resistance and law reform. Signs: Journal of Women in Culture and Society, 38(4), 1031-1055. 
Stryker, S., \& Whittle, S. (Eds.) (2006). The transgender studies reader. New York: Routledge.

Stryker, S. (2007). Transgender feminism: Queering the woman question. In: S. Gills, G. Howie, \& R. Munford (Eds.), Third wave feminism. A critical exploration (pp. 59-70). New York: Palgrave MacMillan.

Stryker, S., Currah, P., \& Moore, L. (2008). Introduction: Trans-, trans, or transgender? WSQ: Women's Studies Quarterly, 36(3\&4), 11-22.

Stryker, S., \& Currah, P. (2014a). Introduction. TSQ: Transgender Studies Quarterly, 1(1-2), 1-18.

Stryker, S., \& Currah, P. (2014b). General editor's introduction. TSQ: Transgender Studies Quarterly, $1(3), 303-307$.

The GIRARE Project (2017). Gender identity registration and human rights effects. Retrieved from: http://girare.sites.uu.nl/

Valdez, L. (1973). Pensiamiento Serpentino. In L. Valdez, Early Works: Actos, Bernabe and Pensamiento Serpentino (pp...-...). Houston: Arte Publico Press.

Villanueva Toscano, S. (2013). Teaching as a healing craft. Decolonizing the classroom and creating spaces of hopeful resistance through Chicano-Indigenous pedagogical praxis. The Urban Review, 45(1), 23-40.

\section{About the authors}

Aurora Perego has recently graduated from the RMA Gender and Ethnicity (Utrecht University). Her research interests concern borders, migration, gender, and sexuality.

Dr Christine Quinan is Assistant Professor of Gender Studies at Utrecht University. Christine works at the intersection of queer/trans studies, postcolonial studies, and critical security studies. With Dr Marjolein van den Brink (Law, Utrecht University), Christine collaborates on a project entitled Gender Identity Registration and Human Rights Effects (GIRARE). 